whole animal kingdom, from the elephant to the flea, instead of dividing them into species.

The following table gives the mean secular parallaxes for different magnitudes and spectral types, the former being visual on the Harvard scale :

$\begin{array}{lllllll}\text { Mag. B stars } & \text { A stars } & \text { F stars } & \text { G stars } & \text { K stars } & \text { M stars } \\ \text { I.0 } & 0.138 & 0.253 & 0.591 & 0.627 & 0.362 & 0.172 \\ 2.0 & 0.092 I & 0.170 & 0.392 & 0.422 & 0.24 I & 0.116 \\ 3.0 & 0.0622 & 0.115 & 0.267 & 0.285 & 0.163 & 0.0786 \\ 4.0 & 0.0422 & 0.0780 & 0.182 & 0.192 & 0.110 & 0.0537 \\ 5.0 & 0.0285 & 0.0526 & 0.123 & 0.129 & 0.0749 & 0.0361 \\ 6.0 & 0.0192 & 0.0355 & 0.0827 & 0.0876 & 0.0506 & 0.0244 \\ 7.0 & 0.0130 & 0.0240 & 0.0560 & 0.0599 & 0.0342 & 0.0163 \\ 8.0 & 0.0087 & 0.0161 & 0.0379 & 0.0403 & 0.0231 & 0.0108 \\ 9.0 & 0.0059 & 0.0109 & 0.0254 & 0.0271 & 0.0156 & 0.0073\end{array}$

The small values near the end of the final column show that these distant $M$ stars are giants nearly equivalent to the $B$ stars in absolute magnitude. On the other hand, the $M$ stars mentioned on page vii. as being $17 \frac{1}{2}$ magnitudes fainter than the $B$ stars are dwarfs.

\section{Universities, Research, and Brain Waste}

THIS is the subject of a presidential address by Prof. J. C. Fields to the Royal Canadian Insti. tute, Toronto, on November 8, I9I9. It contains a review of the relations which must subsist between universities and research and between research and the progress of the world in civilisation, and it opens up so many aspects of these questions which are debatable that for that very reason it ought to be read extensively. Though, on the whole, Prof. Fields's views are consolatory to us in the Mother Country, they also show how much has yet to be done in England, as in other countries, to prevent or reduce the waste of potential brain power in the generations to come. Conditions are now greatly improved whereby the educational net is able to select out of the masses of population the individuals whose mental qualities deserve and, in the interest of the community, require due cultivation, but for the full benefit we must wait a generation or two.

It is premature to make comparisons between the different races and nations in respect to intellectual qualities, but it seems to be incontestable that the Germans have for generations been distinguished by their respect for learning and intellectual achievement, and this is illustrated by the way in which during the war their highly trained men were preserved from too much risk. The Allies, on the other hand, took no special care to protect and preserve such men as Moseley, who was allowed to sacrifice his life in Gallipoli. Such waste is, as Prof. Fields says, a tragedy of the first order. But there is similar waste going on every day in the neglect to give every boy of promise an open road to the university and the right kind of teaching when he gets there.

It is a question open to discussion whether the opportunity to do research lies only in a university career. The successive great discoverers at the Royal Institution in London, from Davy and Faraday onwards, and men like Joule, who was a brewer, and others unconnected with educational institutions, rise at once to mind. But it certainly is true that in the universities the example, the methods, and the spirit of research should be found associated with the teaching in every faculty and in every department.

Prof. Fields was severe on the constitution and government of the American universities, but while it appears to be true that most of the professors there are overworked and that the standard of attainment among the graduates is inferior to those of the universities of Europe, the work that has been done at Johns Hopkins, Baltimore, and Harvard Universities must not be forgotten. Probably the next generation on both sides of the Atlantic will profit by the inter. change of visits by representatives of the higher educational institutions and by the opportunities for exchange of students, both graduate and undergraduate. It is probable also that there is still great ignorance, especially among the masses of the people in all countries, of the fact that the most potent factor in bringing the world out of barbarism to its present better condition of life has been science. "Is it not," Prof. Fields says, "of the first importance that every boy and girl should be made aware of this fact?" With that object in view modern history requires to be taught by teachers better qualified than in the past.

\section{The Sun as a Weather Prophet.}

SOME forty years ago Prof. Langley, while engaged on his eariy bolometric work on the sun, grasped the principle that, inasmuch as solar radiation is the governing factor in world meteorology, it should ultimately become possible to forecast weather changes, so soon as sufhcient information had been obtained in regard to the mechanism of the radiation effect, by continuous observation of the intensity of radiation. Gradual improvement in instruments and methods has enabled his successors to state positively that the socalled "solar constant" is subject to variations of long and short period, and of late years determined attempts have been made, chiefly by the Smithsonian observers, to trace the meteorological changes that may fairly be attributed to these variations. It is clear that there are, from time to time, disturbing factors of apparently terrestrial origin-for instance, the eruption of Mount Katmai, in Alaska, in 1912, brought a promising summer to an abrupt and chilly closse in mid-July; but it is becoming more and more probable that the Smithsonian investigation is on the right lines, and will give definite aid to forecasting, at any rate in tropical and sub-tropical regions.

Publication No. 2544 of the Smithsonian Miscellaneous Collections (vol. 1xxi., No. 3) is devoted to a full statement of the case as regards Argentina, Chile, and Brazil in connection with regular observations of solar radiation at the new solar observatory at Calama, in Chile. Clear evidence is provided by the temperatures found at Buenos Aires that high values of solar radiation are followed by maximum values of temperature at an interval of nearly eleven days. The interval is not the same for lower maxima of radiation, and the amount of lag appears to be connected with the latitude of outbreaks on the sun, but more remains to be explained than the solar rotation will cover. The lag is also not the same for all stations considered. Twenty such were chosen in the countries mentioned, and differences are noted in the intensities as well as in the intervals, and also between the effect of longer and shorter waves. The observations do not cover every dav, so that the correlation is probably not so good as it would be if complete data could be provided. The change due to a variation of $I$ per cent. in the solar radiation appears to range between $0.2^{\circ} \mathrm{C}$. and $0.8^{\circ} \mathrm{C}$. in the tropics; in the temperate zones the effect, though less direct, is greater, even exceeding $2^{\circ} \mathrm{C}$. at some stations.

Having thus obtained satisfactory evidence that, with the exception of the diurnal and annual variaNO. 2652 , VOL. IO5] 